\title{
CHANGE, CONSTANCY, AND CREATIVITY: THE NEW ECOLOGY AND SOME OLD PROBLEMS
}

\author{
BRYAN NORTON
}

The New Ecology emphasizes change and dynamism in ecological systems, claiming that ecology has under-emphasized these features of natural systems and their organizational structures. This emphasis reminds me of a discussion that occurred on the first day of one of my courses in Environmental Ethics. The course mainly covers modern philosophies and attitudes, but I usually spend the first day talking about the ancient background of our modern ideas. I had just spoken of the emphasis in the Hebrew tradition on the eternal nature of Jahweh, and had gone on to expound on the fascination of early Greek philosophers with change and permanence. I noted that the precocious Heraclitus had proclaimed, "All is in flux," but that Parmenides, who denied even the possibility of change, was more representative of Greek thought. ${ }^{1}$ I explained how Plato had declared the changing world of the senses illusory because this world lacked the stable and unchanging status of "Ideas" or "Forms."2 For Plato, only the constant and unchanging could be real. Then, a student asked perhaps the best question I have encountered in over twenty years of teaching: Why do the Judaeo-Christian tradition and the Greek traditions share the same reverence for the fixed and unchanging?

Philosophy, at its best, identifies and questions our deepest assumptions. The student had noticed that both the Hebrews and the Greeks, so different in other respects, apparently gravitated toward static, everlasting, ultimate explanations of the confusing and highly changeable world they encountered experientially. I paused and then

* Professor, School of Public Policy, Georgia Institute of Technology.

1. See G. Kirk \& J. Raven, The Presocratic Philosophers (1966).

2. See id. 
gave some answer I do not remember. This question, however, was too good for an off-the-cuff answer. Having thought about the question until the next class meeting, I had a better, but still very unsatisfying answer. I had to admit that I could see no philosophical or intellectually defensible principle that could justify such a monumental assumption. My answer was that there seems to be a deep psychological need for constancy and stability in Western cultures, perhaps in all cultures. Somewhat lamely, we left the matter there and proceeded to discuss the rise of modernism. Fortunately, the topic of this special issue, change in ecological systems, provides an opportunity to return to this important question: How are we to conceptualize the rich mix of change and constancy that we encounter in the world of experience?

The New Ecology has attacked traditional ecological thought (what I will for convenience call "The Old Ecology") for emphasizing constancy, stasis, and equilibrium in describing ecological systems, and for under-emphasizing the role of change, disturbance, and dynamism. I tell the above anecdote because it occurs to me that the readiness of ecologists to embrace equilibrium theories and to find constancy in ecological events may have deep-perhaps even nonrational-sources. Equilibrium theories may not be empirical theories at all, but rather may represent pre-theoretical assumptions, which are perhaps rooted in a deep, psychological need for stability in the face of threatening changes. Ecologists, too, are affected by psychological needs. If my speculations about the depth of the Western commitment to stability have any merit, we might acknowledge that we have no choice but to find some level or type of stability. The intellectual question then becomes one of how to characterize stability and how to reconcile it with the empirically obvious change we experience everywhere.

\section{Two ARguments Against the "Old ECOLOGY"}

The question before us is: How will the ideas of the "New Ecology" affect environmental thought and environmental goals? I will begin to answer this question by distinguishing two arguments, both based in the New Ecology, which lead to two distinct criticisms of the Old Ecology. ${ }^{3}$

3. My purpose here is not to capture the fine nuances of either argument, but rather to show their skeletal structure and emphasize the differences between them. I have no doubt that the proponents of the arguments would refine them and perhaps even show linkages 


\section{A. The Argument from Constant Change}

According to the argument from constant change, the Old Ecology was unaware that ecological systems are dynamic, changing systems. The Old Ecologists treated unchanging systems as the norm and therefore assumed that stasis is natural and that change requires explanation. Old Ecologists understood change as ultimately tending toward a climactic state of mature stability. Disturbance was treated as a temporary derailment of the ecological train; the natural tendency was to build structure and to regain the stable, climactic state.

This emphasis on equilibrium systems negatively affected management practices, according to New Ecologists, because it encouraged managers to assume that they could exploit a particular species or resource while assuming the system would be unaffected in deep and lasting ways. In the old models of management, exploitation-driven changes in the system represent only temporary deviations from a steady state. Insults to ecological systems can therefore be healed simply by relaxing harvesting pressure or reducing direct damage to resources; the system can be expected to go back to "normal."

According to the New Ecologists, it is dangerous to assume that ecosystems are equilibrium systems capable of absorbing insult and returning to their pre-disturbance state. This line of reasoning is sometimes carried further to suggest that, since the goals of environmental protection have so often been formulated in the vernacular of the Old Ecology, full recognition of the importance of change will necessitate a major rethinking of environmental policy goals.

\section{B. The Argument against Grand Theory}

One can also find a second critique of old-style managers in the writings of New Ecologists. According to this second argument, Old Ecologists over-emphasized grand and speculative theory while New Ecologists pay less attention to general principles of ecosystem organization and study particular, local ecological interactions and their outcomes. While New Ecologists are careful to deny that they

\footnotetext{
between them. Because these initial sketches are intended to show the broad outlines of the arguments, they are not attributed to any specific author. More specific attributions, with citations, follow.
} 
are anti-theory, they insist that theory must be built from the bottom up, by generalization from many specific studies, rather than from the top down, with broadly applicable hypotheses deduced from general principles of structure. According to the argument against grand theory, Old Ecology and old management can be faulted for letting a few grand and psychologically satisfying general theoretical. principles guide their activities and for neglecting studies that reveal the special character of particular assemblages of species. If ecology is reformed, according to this second argument of New Ecologists, ecologists and environmental managers should avoid grand generalizations and emphasize local ecological knowledge in support of locally formulated environmental goals. ${ }^{4}$ Rather than pontificate about damage to "nature's fabric," ecologists and environmental managers will, once corrected by New Ecology, have to form local coalitions, in which ecologists provide ecological information and support for local efforts to protect systems under stress.

\section{Responses to the Arguments of the New Ecology}

I will consider both arguments in light of their potential impacts on the future of environmental policy. The arguments are clearly stated by Daniel Botkin:

Admitting that change is necessary seems to open a Pandora's box of problems for environmentalists. The fear is simple: Once we have admitted that some kinds of changes are good, how then can we argue against any changes against any alteration of the environment? ${ }^{5}$

While Botkin goes on to explain that there are more or less comforting answers to this question, and that eventually progress will ensue as we develop new approaches consistent with an ecology of change, his discussion is motivated by two claims: (1) that environmentalists and environmental managers have not been aware of the dynamic nature of ecological systems; and (2) that once they do become aware

4. See generally P. Price, Alternative Paradigms in Community Ecology, in A NEW Ecology: Novel APPROACHES to INTERACTIVE SYSTEMS 353 (P. Price et al. eds., 1984); Mark Sagoff, Ethics, Ecology, and the Environment: Integrating Science and Law, 56 TENN. L. REV. 77 (1988).

5. DANIEL BotKIn, Discordant HaRMONIES 156 (1990). 
of this dynamism, they will at least initially face a new set of problems in developing and defending their policies.

Botkin is correct to claim that environmental managers have often overlooked the importance of change and that they have often acted as if their exploitation of a species or resource would have no impact on the organization of the larger ecological system. He is also correct in implying that this failure to recognize the importance of change in natural systems has led to tragic failures of management. I disagree, however, with Botkin regarding the exact analysis of what has gone wrong. In order to see the difference between my approach and that of Botkin, I must introduce two qualifications to Botkin's argument: (1) that the idea of developing and using dynamic models has been around for a long time but that problems occur with details of their implementation; and, (2) New Ecologists, acting in reaction to the prior over-emphasis on the grand theory of stability in ecological systems, sometimes over-emphasize the importance of change in ecological systems.

The first qualification is historical in nature. Consider the following quotation:

To the ecological mind, balance of nature has merits and also defects. Its merits are that it conceives of a collective total, that it imputes some utility to all species, and that it implies oscillations when balance is disturbed. Its defects are that there is only one point at which balance occurs, and that balance is normally static. ${ }^{6}$

According to Professor Botkin's arguments, I assume he would agree with this statement. The interesting thing about this quotation, however, is that the passage was published over 50 years ago in 1939 by Aldo Leopold. During the 1930's and 1940's, Aldo Leopold, author of $A$ Sand County Almanac and a hero to conservationists as the father of the land ethic, developed a general theory of dynamic environmental management based on ecological theory. This quotation represents a step in the evolution of that remarkable theory of management. ${ }^{7}$ It could hardly be said that Leopold failed to share his insight with other environmental managers since the paper was published in The Journal of Forestry, a leading journal of environmen-

6. Aldo Leopold, A Biotic View of Land, 37 J. FORESTRY 727 (1939).

7. BRYAN NORTON, TOWARD UNITY AMONG ENVIIRONMENTALISTS 51 (1991). 
tal management. Further, this passage was not unique but represented a fascination with the topic of change and scales of change, to which Leopold returned throughout his career, most notably in the famous simile of "thinking like a mountain." Leopold first became interested in ecology and the study of ecosystems when he attended a conference on natural cycles, which was devoted to the theoretical and practical question of how one can identify changes that are part of natural cycles and distinguish these from changes that result from human stressors. ${ }^{9}$ At that conference he met Charles Elton, the distinguished British animal ecologist, and the two became friends and collaborators in theoretical and field studies of ecological systems. ${ }^{10}$ Therefore, the idea that natural systems are dynamic and changing and that the use of equilibrium models in management represents a simplification and even a falsifcation of natural systems has been present in ecology and environmental management for at least fifty years. Leopold and others recognized that equilibrium assumptions produce, at best, useful models that should always be qualified and supplemented with more dynamic models. Consequently, there can be no doubt that Leopold and his disciples took dynamism very seriously and that they tried, however unsuccessfully, to base their management on this insight.

If Botkin is right that environmental managers, through the present, have continued to act as if they are unaware that natural systems are dynamic, then we are faced with more questions. Why have environmental managers failed, in a half century, to recognize and implement Leopold's clearly-stated insight? Why should we think that Botkin's argument is going to have stunning effect, while Leopold's did not? Surely, we know more about change in ecological systems than we did in Leopold's day, so we can no doubt cite scientific, ecological studies describing dynamic systems. But if Botkin's argument is correct, we cannot really trust that science after all - it is tainted because the models used to develop that scientific base were faulty. So again, why should we think Botkin's clear restatement of Leopold's doctrine of dynamism in nature will have more effect this time around? To answer this question fully, we may have to look beyond the failure of scientific insight. It may be that the reliance on assumptions of equilibrium and stability are more

8. Aldo Leopold, A Sand County Almanac 129-33 (1966).

9. CURT MEINE, Aldo LeOPOLD: HIS LIFE AND WORK 283 (1988).

10. Id. 
psychological than rational. While $I$ agree that Botkin is right to point out the failure of both ecologists and environmental managers to develop and use dynamic models, it is important to recognize that the basic idea has been around at least since Leopold. The Devil, it turns out, is in the details.

The second qualification to Botkin's arguments concerns the possible overreaction of New Ecologists. Because they are writing in reaction to decades of over-emphasis on stasis, stability, and unidirectionality in the development of ecological systems, New Ecologists sometimes over-emphasize the pervasiveness of change. It is not a good idea to pose the question of change versus stability in nature as if there may be an all-or-nothing answer, as if it might turn out that the world is either entirely changing or entirely stable. Both extremes were explored by the Greeks. Heraclitus, as noted, believed "[a]ll is in flux;" Parmenides, at the other extreme, concluded that all change is illusory. ${ }^{11}$ The truth surely is somewhere in between.

Accordingly, I doubt New Ecologists intend to deny all constancy in nature. For example, they clearly accept the basic assumptions of the evolutionary/ecological world view - that species, over many generations, adapt to regularities in their environment. Evolutionary theory demands that nature be sufficiently patterned so that a species can be shaped, through many repetitions of births and deaths, by natural selection. New Ecologists do not reject this basic assumption of all evolutionary/ecological theory - there must be enough pattern and predictability in the environment for populations to evolve and adapt to it. Their point, rather, is that change is more important, and constancy less important, than has been assumed by Old Ecologists.

Specifically, this means that disturbances can and should in many situations be thought of as expected and normal, and that many, perhaps most, communities are regulated more by disturbance than by some tendency toward climax. However, it does not mean ecological systems contain nothing that is constant or predictable. The tree species that survive in fire-regulated communities - often cited as examples of disturbance-driven systems - have adapted to a pattern of periodic fires. The point is not to choose between change and constancy, but to achieve a better conceptualizaton of the confusing mix that we see in ecological communities.

11. See KIRK AND RAVEN, supra note 1. 


\section{RE-THINKING ECOLOGICAL CONSTANCY}

If we are to make sense of New Ecologists' justified emphasis on change, I believe their view must be given a scalar, hierarchical interpretation. We must recognize that every level of nature is constantly changing, but the overall process is driven by an interplay between relative change and relative constancies on different levels of a complex hierarchy. Nature is organized into a scalar hierarchy in which each level reacts to, and is also affected by, levels below and above. These effects decrease in directness and force as one goes up or down the hierarchy. ${ }^{12}$

We have a simple hierarchy of living systems. Each level representing a different dynamic, changing at slower and slower paces as we move outward, from cell to community. Scale is therefore the key to a hierarchical understanding of ecosystems. In a hierarchical world, scale, not only temporal scale, but also spatial scale, is crucial to all understanding. Nature can best be understood as an organization of systems and subsystems, with larger systems changing more slowly than their constituent subsystems. The larger systems therefore provide a relatively constant background to which smaller subsystems can adapt. This constant background can be conceptualized as a complex mixture of constraints and as opportunities that present themselves to smaller, adaptive subsystems such as individual organisms.

Stability in nature may be called a well-founded illusion. It is an illusion because, as Heraclitus, Leopold, and Botkin tell us, nature changes at every scale. It is, nevertheless, well-founded because huge differentials in the scale of Earth's processes are adequate to provide a workable sense of relative stability, stability that is experienced comparatively. Slowly changing background variables are relatively static in contrast to rapidly changing variables resulting in the appearance of stability. For instance, as a prime example of the pervasiveness of change, Botkin cites the discovery thirty years ago that the Earth's surface is actually composed of dynamic, tectonic plates that have literally changed the face of the earth in the longer scales of geological time. ${ }^{13}$ Imagine yourself as a common housefly for a moment, trying to reproduce young and pass on your genes to

12. See Bryan Norton, Ecological Integrity and Social Values: At What Scale?, 1 ECOSYSTEM HEALTH 228 (1995).

13. BOTKIN, supra note 5 , at 145 . 
a future generation. Houseflies go through their whole life cycle in a few days. About 1.03 million generations of houseflies will be born and die in the time it takes the San Andreas fault line to move one mile. To a housefly, the chance of being run down by a tectonic plate would not be a major limiting factor in the reproductive process. Relative to housefly-time, tectonic change is imperceptible - the location of the continents occurs on a different scale - the continents are stable enough not to matter to individual houseflies. I could have given other examples, such as drosiphila, providing even larger numbers or smaller numbers, such as those for generations of humans. The point is that these numbers are all very large. Movements of tectonic plates are not a major determinant of human evolution because the pace of change in tectonic plates is so out of proportion to the scale of events in ordinary human lives. While the tectonic plates are changing, they change so slowly that for purposes affecting survival of human individuals the plates are stable. ${ }^{14}$

The principle point is that, even though everything is constantly changing, not everything changes at the same rate. Differences in temporal rates are so great that from any given perspective there will be environmental factors that are relatively constant, to a degree permitting the necessary adaption a species requires to maintain their niche. Thus, while it is true that nature changes on every level, it is also true that there are layers upon layers of "relative stability."

I will now explain how my analysis of the failure of environmental management differs from Professor Botkin's. The reason environmental managers have not made use of Leopold's insight is due to the inability to operationalize Leopold's elegant theory of dynamic management. Leopold's theory has not been operationalized because no one has developed adequate conceptual tools for understanding the pace and scale of change in multi-layered ecosystems. ${ }^{15}$ Once we follow Leopold and Botkin into the world of dynamic ecological management, we face a hopeless confusion of scalar models with few rules for organizing them. As Stuart Pimm has recently emphasized, ecologists seldom do studies that can test ecological processes on scales longer than a few years. ${ }^{16}$ For example, the National Science Foundation's limit for project funding

14. For a more technical explanation of this point, see generally Bryan Norton \& $\mathbf{R}$. Ulanowicz, Scale and Biodiversity Policy: A Hierarchical Approach, 21 AMBIO 244 (1992).

15. NORTON, supra note 7, at 39-60.

16. Stuart Pimm, Balance of Nature? 1-4 (1991). 
is usually three years. Much of the theory explaining long-term processes in nature has therefore been based more on analogies and assumptions than on hard ecological evidence. ${ }^{17}$ Very little is known about large-scale, slow processes in nature; to my knowledge, no one has an algorithm for "scaling-up" from small-scale and short-term studies to large-scale and long-term studies.

It is one thing to say, as Leopold clearly did, that nature is composed of many dynamic processes and that scale is crucial; it is quite another thing to furnish a detailed set of concepts for discussing change and its impacts across differing scales of time and space. I believe that hierarchy theory, explicitly stated in the early 1980's, provides a beginning for fashioning such tools. ${ }^{18}$ It might be argued that the hierarchy theorists simply codified long-understood facts about differential paces of change. At any rate, the introduction and formalization of hierarchical models defines more precise spatiotemporal relationships, which may prove very helpful in conceptualizing applied problems in environmental policy and analysis. ${ }^{19}$

So while Botkin and I agree that we need to apply dynamic theory to the study of ecosystems and environmental management, I doubt that the problem can be solved simply by asserting that we need dynamic models. We actually need to produce the models, which in turn requires an adequate theoretical understanding of multiscalar change. I also do not see this recognition and challenge, as Botkin apparently does, as requiring a radical re-thinking of the goals of environmentalism, although it will require a change in some formulations of environmental goals. I believe that Leopold's land ethic, which emphasizes the protection of the integrity of multi-scalar ecological systems should be our basic guide to management. ${ }^{20}$ According to this view, humans tend to perceive ecological systems on the shorter time scales of particular plots or of individual, useful species, whereas impacts of human management also affect, on longer time scales, the very organization and structure of the larger ecological system. Good management, then, must monitor, in addition to

17. Id. at 3.

18. See generally T.F.H. Allen \& ThOMas B. Starr, Hierarchy: Perspectives FOR ECOLOGICAL COMPLEXITY (1982); R.V. O'NEIL ET AL., A HIERARCHICAL CONCEPT OF ECOSYSTEMS (1986). While I think of hierarchy theory as important in its own right as a theory of system organization in ecology, I refer here to its applications in the normative science of environmental management.

19. See Norton \& Ulanowicz, supra note 14.

20. LEOPOLD, supra note 8. 
short-term impacts, longer-term impacts on the organization and integrity of larger systems. ${ }^{21}$ The puzzle then remains: Why has the health and integrity approach not been implemented in environmental policy?

We can dig deeper for an explanation of the failure of Old Ecology to guide environmental management by looking at the ' second argument of New Ecologists, the argument against grand theory. According to this second argument, New Ecology rejects grand theory and moves toward more local studies of adaptations. Ecologists, according to this view, should correct Old Ecology by forming a coalition with local environmental managers to study the behavior of species and ecosystems at local scales, while trying to understand how local systems fit into larger-scale systems. ${ }^{22}$ This leads us back to problems of scale: cross-scalar impacts are not well understood because we lack both a theoretical understanding and comprehensive practical solutions to the problem of scale in ecology. ${ }^{23}$ Aside from the fact that problems of scale in ecology are enormously complex and difficult, I believe there is an intellectual reason why the problem of scale has not been solved - indeed, has hardly been seriously addressed by ecologists and physical scientists. That reason, which I think expresses the essence of the second argument of New Ecology, is that ecological theorists (and philosophers as well) have, deep down, been captivated by a particular version of the idea of organicism. This idea has caused them to forget the importance of dynamic processes almost as soon as they acknowledge them. ${ }^{24}$ To understand how this has occurred, we must look more carefully at the concept of organicism because it comes in several varieties with very different philosophical implications.

21. Bryan Norton, Context and Hierarchy in Aldo Leopold's Land Ethic, 2 ECOLOGICAL ECON. 119 (1990).

22. Bryan Norton \& Bruce Hannon, Environmental Values: A Place-Based Theory, 19 ENVTL. ETHICS (forthcoming 1997).

23. PIMM, supra note 10.

24. This interpretation is quite consistent with the arguments of New Ecologists; they do not oppose theoretical explanation or generalization, but they oppose the top-down process of filling in the gaps in empirical knowledge with speculative theories about the "strategies" adopted by ecosystems because these general ideas tend to bias specific research and its reporting. See Price, supra note 4. 


\section{ORGANICISM: WEAK AND STRONG VERSIONS}

The following words were scribbled by John Muir in the margins of a book on evolution: "Every cell, every particle of matter in the world requires a Captain to steer it into its place . ... Somewhere, before evolution was, was an intelligence that laid out the plan, and evolution is the process, not the origin, of the harmony." 25 While it may be unfair to hold anyone accountable for what they scribble in margins of books they read, we find Muir adopting an especially strong version of organicism, characterized by two important features. First, he interprets evolution as a process within a whole being in the sense that God and the whole of nature are identical, and, consequently, the whole of nature is, or is like, a person (hence the capitalization of Captain). Second, Muir attributed intentions to this whole Being crediting it with guiding the dynamic processes in nature according to a divine plan. ${ }^{26}$

Muir's comforting and elegant pantheism is therefore very awkward from a scientific perspective. It apparently recognizes a strategy or goal of ecosystem development, and treats that strategy as if it were both a prior, mentalistic end and a causal force - but a causal force for which there is no clear mechanism. The image of strong organicism, by attributing spiritual personhood to the forces of the whole system, tempted later ecologists such as Frederic Clements and Eugene Odum to over-emphasize the holistic characteristic of ecosystems, treating them as acting according to a driving principle. ${ }^{27}$ Holism in ecology has therefore been crippled by its flirtations with mysticism. $^{28}$

25. STEPHEN FOX, JOHN MUIR AND HIS LEGACY: THE AMERICAN ENVIRONMENTAL MOVEMENT 82 (1981) (quoting notes of John Muir in his copy of a book by Alfred R. Wallace).

26. These assumptions are not really independent. Throughout the history of Western thought, to attribute a mental life to a being is taken to be tantamount to giving it a spiritual identity.

27. Frederic EdWARd Clements, Research METhods IN ECOlogy (1905). For a more contemporary example, see E. Odum, The Strategy of Ecosystem Development, 164 SCIENCE 262 (1969).

28. Leopold himself flirted with this seductive, strong version of organicism, but always retreated. Yet $I$ have no doubt that this image of an ecosystem as a unitary and semiconscious being contributed to Leopold's quickness to adopt the organicist formulations of Clements and some of the surely excessive claims for the unidirectionality of succession that were popular in his day. In this respect, Leopld was - like his contemporaries among pure ecologists - seduced by an image of whole ecosystems as shadowy existents which "strategize" and "optimize." In that way, Leopold may require updating, and purging of the oft-hidden assumption of stasis and predictability. 
We have now come full circle, back to the problems arising from Moses, Parmenides and Plato. Why are Westerners so quick to assume that underneath the constant change we actually encounter, no matter how chaotic the events we observe, there is order, constancy, a plan? This leads to a second question. Are we now in the realm of science, or are we in the realm of the deep unconscious, better studied by psychology, philosophy, or religion?

To understand this Western tendency, it may be necessary to look away from science towards these other disciplines. My discipline, environmental ethics, has also contributed to the failure of policy makers and environmental managers to develop an adequate scalar analysis for addressing environmental policy problems. We, just like the ecologists, have been too quick to personalize nature, to think of ecological systems as identifiable entities with a capability of consciousness and explicit goals, and to attribute elements of nature a purpose of their own. I am suggesting that Muir's strong organicism underlies and bedevils both ecology and value theory equally. In ecology, it led to Clementsianism and to unfortunate metaphors like the "strategy of ecosystem development." In value theory, it has encouraged an unfortunate tendency to think ecosystems are sufficiently like persons to justify the extention of inherent value to them.

Why have we been so anxious to consider ecosystems as things at all? Much of the writing in environmental ethics concerns which objects in nature have value of their own and Leopold and Botkin have shown us that ecosystems are not properly understood as objects at all. They are open systems that unfold on many scales, with changing elements on each level making the best of opportunities gained by reaction to relative stabilities in their larger and slowerscaled environment. Environmental ethics has contributed to the failure to escape strong organicism because members of the field have been too quick to embrace the view that, like human individuals, ecosystems can have inherent values. Behind this quickness to embrace ecocentrism is a deep-seated bias toward things and beings, especially personages, at the expense of open processes.

Let me illustrate my point by reference to perhaps the most important passage in the history of conservation thought, Leopold's famous criterion. "A thing is right when it tends to preserve the integrity, stability and beauty of the biotic community. It is wrong 
when it tends otherwise."29 Some advocates of the land ethic, such as J. Baird Callicott and the Deep Ecologists, have taken these two sentences to assert that the community or ecosystem is the object of value which conservationists should be attempting to protect. ${ }^{30}$ They assumed, accordingly, that the ecosystem or community must, for Leopold, be an object of value that exists independent of human values. Callicott and his followers therefore interpret this passage as Leopold's definitive statement that communities themselves have inherent value, human-independent value that can be considered in competition with - and sometimes override - human values.

Leopold's criterion of good behavior, interpreted as an assertion that ecosystems have human-independent inherent value, has led to a sometimes nasty and wholly misguided discussion of whether Aldo Leopold and his followers are environmental fascists or not. Critics of the land ethic, especially Tom Regan, have argued that if we manage to protect ecosystems because they have inherent value, we will sometimes override the rights of individual members (human and nonhuman) of ecological communities for the good of the larger whole. Regan even compared this approach to the way that Adolph Hitler and the Nazis overrode the rights of individuals in their misguided attempt to protect the German state as the embodiment of a master race. ${ }^{31}$

However, if Leopold and the land ethic are interpreted within a multiscalar system, there is no conflict between individual rights and the protection of ecosystems. Human individuals actually exist within ecosystems. Damage to ecosystems is usually the cumulative damage of whole cultures and civilizations - it is a responsibility at the community level of a multi-scaled, open system, not at the level of individual decisions. Correction of these communal threats need not override the interests of individuals. Individuals, in a properly functioning system, will act in ways that contribute to, rather than destroy, the values that emerge on the larger, ecosystem scale.

In the end, it is questionable whether the whole issue of fascism and intrinsic value in nature would arise if we could keep clearly in our mind that ecosystems are open processes. Would interpreters of Leopold be likely to say, without the ghosts of strong organicism

29. LEOPOLD, supra note 8.

30. J. Callicott, In Defense of the land Ethic (1989); Bill Devall \& George Sessions, DeEP ECology: Living AS IF NATURE MATtered 86 (1985).

31. TOM REgAN, THE CASE FOR ANIMAL RIgHTS 362 (1983). 
influencing their conceptualizations, that ecosystem processes have inherent value? Environmental ethicists have been encouraged to find inherent value in ecological systems because they saw them, in the great tradition of Muir, as personalized organisms. ${ }^{32}$

Being constantly tempted to think of ecosystems as persons - or at least as objects capable of strategizing - philosophers and ecologists have unfortunately failed to confront an ancient philosophical problem: How can an organism behave independently while at the same time functioning as a part of a larger organism? In philosophy, it is called the problem of parts and wholes. In ecology, it is called the problem of scale. Because they pay attention only to wholes, as is required by their implicit devotion to personalistic, strong organicism, ecologists and philosophers have had little reason to address the problems of parts and wholes and the related problems of scale, boundaries, and pace of change.

\section{RESPONDING TO ORGANICISM}

Botkin is correct in asserting that dynamism is absolutely necessary to move beyond obsessions with organicism and teleology. This, however, is not enough. We must shift the ground of debate regarding environmental values so that issues of scale become paramount. We must do so by proposing a clear conceptual framework for discussing the scale and pace of change. That ecologists have not solved the problems of scaling up from their small studies to larger and longer-term ones is perhaps excusable. The problem is admittedly a tough one. What is scandalous, given its importance for environmental management, is that ecologists and philosophers have hardly addressed these problems at all.

32. We can also consider another interpretation of Leopold's famous remark, as a comment on the proper focus of conservation management rather than a statement of which objects in nature are of value. Leopold may have been making the point that, because of the complexity of nature's interrelationships and because there are so many different values exemplified in nature on so many scales, the only way to protect these values is to protect the integrity of community processes. Protecting the integrity of biotic systems, taken together with the complementary guidelines - stability and beauty - is the goal of good environmental management. According to this interpretation, Leopold is not telling us what to value in nature, but rather telling us what to protect in our practical environmental management. Leopold is defining the correct action in environmental use and management. Furthermore, he is strongly endorsing a systems approach to environmental management as the only way to encompass our multifarious goals as we manage a multi-level, complex system that is our habitat. 
Emphasizing wholes, rather than the interrelationships of parts, has encouraged an unfortunate ambiguity in Leopold's central term, integrity, and this ambiguity has impeded its application. As Leopold intended the term, the integrity of an ecosystem is the integrity of an open, non-conscious complex of processes unfolding at different paces and scales. All of these ideas can be explained scientifically, without a hint of teleology or mysticism..$^{33}$ However, when the term integrity is applied to a whole being, it is natural to also understand integrity as an attribute of a personal being. As a personal attribute, integrity may carry moral weight in opposition to our obligations to human beings. It is a tragedy that Leopold's insights have been unnecessarily linked to unscientific speculations as a consequence of this potentially dual meaning, making them seem unnecessarily radical and open to endless debate. We must get past personalist organicism and address the key issue of system integrity for dynamic, nonlinear systems, and develop concepts for understanding multi-scalar interactions within ecosystems and the processes that constitute them.

The difficulty in all of this, of course, is that organicism does have an important point to make. ${ }^{34}$ Organicists are correct that mechanistic models do not explain the ability of ecological processes to create, sustain, and heal themselves. Ecological management cannot begin without accepting two elements of organicism's richer conception of nature - the idea that the whole is more than the sum of its parts, and the idea that relationships among multi-scalar processes, not the static characteristics of objects, provide the key to understanding ecosystems as they evolve through time. The problem is to express this idea in a way that does not carry us all the way to teleology and strong organicism. We must emphasize the creative nature of environmental processes and the key role of energy flows in those processes without personalizing them.

Hierarchy theory may provide the middle ground between inadequate forms of mechanism and the unfortunate personalism of strong organicism. We might call this viewpoint minimalist organicism. Hierarchy theory views ecological systems as complex, multilayered systems that are self-organizing. This view does not involve causal mechanisms that work from the top down, but rather posits complex communication both upward and downward across all levels

33. See R. Ulanowicz, GRowtH AND DEVElopMENT (1986).

(1991).

34. Bryan Norton, Should Environmentalists be Organicists?, 12 TOPOI 21, 21-30 
of nature. Creativity is not directed by a unified figure; it emerges from the ability of living things to adapt to relative constancies in their environment. Any system that is self-organizing exhibits this creative force, which we now know depends upon a mix of stable, predictable elements and chaotic, unpredictable ones. ${ }^{35}$

In a hierarchy, behavior of individual organisms responds and adapts to patterns and processes at the system level. This behavior is analogous to one sense of individual freedom - the freedom to act independent of constraint, the ability to choose between available options, and to adapt in an effort to survive, prosper, and leave successors. In a dynamic, irreversible system, time is necessarily asymmetrical. Constraints flow down the hierarchy, but information flows upward in the system as well. The aggregated choices of individuals are component processes in the larger, landscape-scale environment. Individual behavior is enacted against a stable backdrop, or environment, which appears to individual choosers as a mix of opportunities and constraints. In essence, individuals appear both as individuals on one level and also as parts in a larger dynamic system.

In a longer frame of time, the cumulative impacts of individual choices reverberate as changes in the environment, altering the ratio of opportunities to constraints faced by future persons. The intergenerational impacts of a culture on the landscape can therefore be understood in terms of cross-generational exchanges in which the operative currency is freedom (options) expressed as a ratio of opportunities to constraints. These opportunities are stored in the structure of an ecological system. If growth in human impact erodes natural capital stored in ecological systems on larger and slower time scales, future generations will face more constraints and fewer opportunities as the cumulative impact of many individual human actions skim off opportunities (such as capital stored in ancient forests) and leave constraints (poor and eroding soil exposed by clearcut lumbering). Alternatively, if resources are protected and if important and productive ecosystem processes are maintained, the people of the future will, as we have, face an abundance of opportunities. $^{36}$

\footnotetext{
35. See generally ROGER LEWIN, COMPLEXITY (1992) (describing how this is possible for a system).

36. The relationship between opportunities/options and our obligations to the future is explored in more detail in Norton, supra note 12 , at 228-41.
} 
Ecological systems thus should be modelled as dynamic, open systems that are organized asymmetrically in space and time. Human economic systems represent dynamics driven by choices of individuals who live, choose, and die in cycles that are rapid in comparison to the rate of change in the surrounding environment. Regularities and predictable patterns on these larger levels provide the opportunity for biological and cultural evolution. Human individuals interact with their environment, usually through the mediation of an economic system. Individual perception, accordingly, is geared to short-term changes that occur in economic time. Large-scale ecological impacts of human activities must be understood both as results of cumulative individual actions on one scale and as spill-over impacts on larger scale environmental systems that would normally change so slowly that their dynamic is unnoticed by short-sighted humans. In this way, individual decisions made within an economic system can, when acting cumulatively with the impact of many other individuals, affect the breadth of options open to the future.

One prerequisite for charting a rational environmental policy is to analyze the cumulative impact of many individual decisions on these larger and normally slower scales, because accelerated change at these scales may affect the context in which future members of our society will face choices and adapt. Using his own spruce-budworm research and supplementing it with several other examples, C. S. Holling argues that when human activities simplify processes by concentrating productivity into a few crops or species, they can make large-scale systems more ecologically "brittle."37 Because this style of management decreases the redundancy of pathways fulfilling such essential functions as energy transfer, the system becomes more prone to shift into a new steady, functional state, one that is less likely to be supportive of the cultural and economic behavior and adaptations that have emerged in response to the opportunities available in local environments.

Accordingly, Holling has proposed that we must recognize two concepts of resilience. ${ }^{38}$ One concept, which operates at the economic or engineering level of the system, assumes a single stable point to which the system, once disturbed, will return. This concept is

37. C.S. Holling, Cross-Scale Morphology, Geometry, and Dynamics of Ecosystems, 62 ECOLOGICAL MONOGRAPHS 447, 483-485 (1992).

38. C.S. Holling, Engineering Resilience versus Ecological Resilience, in ENGINEERING WITHIN ECOLOGICAL CONSTRAINTS 31 (Peter Schulze ed., 1996). 
appropriate for individuals to apply in making day-to-day economic decisions - it assumes system organization and behavior will be unaffected by an individual decision and develops equilibrium models to understand human behavior on the individual level. The other concept of resilience, ecological resilience, becomes relevant when the concern is to understand whether the cumulative impact of individual decisions may shift the larger ecosystem into a new stable state of functioning. Since such new stable states are almost always less desirable for humans, it is important that environmental management be formulated and evaluated on both the short-term, single-state model and on the longer-term model that monitors whether cumulative impacts are threatening to exceed a threshold and cause a flip into a new system state.

\section{SUSTAINABILITy in RElatively Stable ECOSYSTEMS}

In closing, I would like to show how one might build a scalar analyis, based in hierarchy theory, into a responsible approach to environmental policy formation and implementation. This approach starts from the moral axiom, based in the principle of fairness across generations, that no generation justifiably may destroy the complex and creative processes of nature. This principle, which we can call the Sustainability of Processes Principle, protects not particular elements of nature, such as genes, individuals, species, or ecosystems, but instead protects the integrity of ongoing processes of nature. Once this moral principle is established, it is possible to use hierarchy theory to introduce some order into the conceptual chaos that afflicts our understanding of the natural systems within which we live and act.

To illustrate this, I use a device called a Risk Decision Square, which leads to a two-tier decision process based on natural scales. ${ }^{39}$ The neutral version (Figure 1) maps decisions according to their reversibility and their physical scale. The Square plots the degree of reversibility of an impact of some human activity across the horizontal axis and the magnitude of that impact on the vertical axis. On the horizontal axis, we use the common sense idea that if an impact of some decision we make in the present is easily reversed, we consider it less dangerous, and are more willing to accept it as justified. On the vertical axis, we recognize, in a likewise common sense manner,

39. Bryan Norton, Evaluating Ecosystem States: Two Competing Paradigms, 14 ECOLOGICAL ECON. 113, 119-123 (1995). 


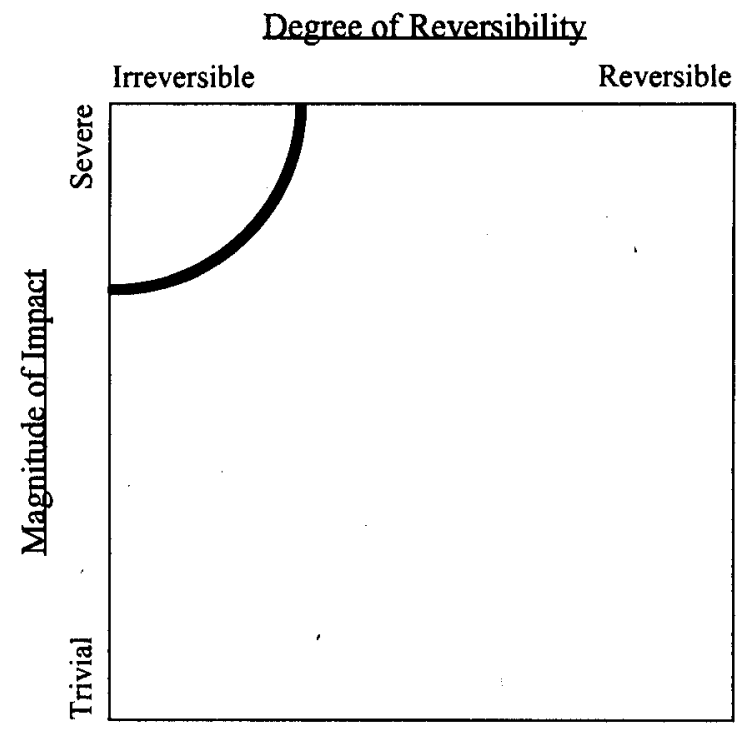

Fig. 1. Neutral version.

that the greater the impact of a decision, the more likely we are to question its wisdom. I think it is reasonable, then, to say that this square represents the moral space in which reasonable people would discuss decisions affecting our environment. I also think that reasonable people would be willing to accept risks that fall in the region of trivial impacts, in the region of easily reversible impacts, and in the region where impacts are both trivial and reversible. These decisions should not affect future generations significantly or negatively, and can therefore be considered as decisions that are resolvable on the scale of individual choice. This region is therefore ruled by individualistic criteria, such as a criterion of economic efficiency corrected for interpersonal fairness and equity. As decisions involve greater impacts and become less reversible, we are more inclined to invoke the sustainability principle and to use moral language to invoke moral injunctions. The system of analysis proposed is therefore two-tiered, separating a realm of decisions that are open to individual choice from a second realm that is governed by the moral principle of sustainability and intergenerational equity.

Having seen how the general framework of a Risk Decision Square can illuminate our discussion of environmental risk, we can 


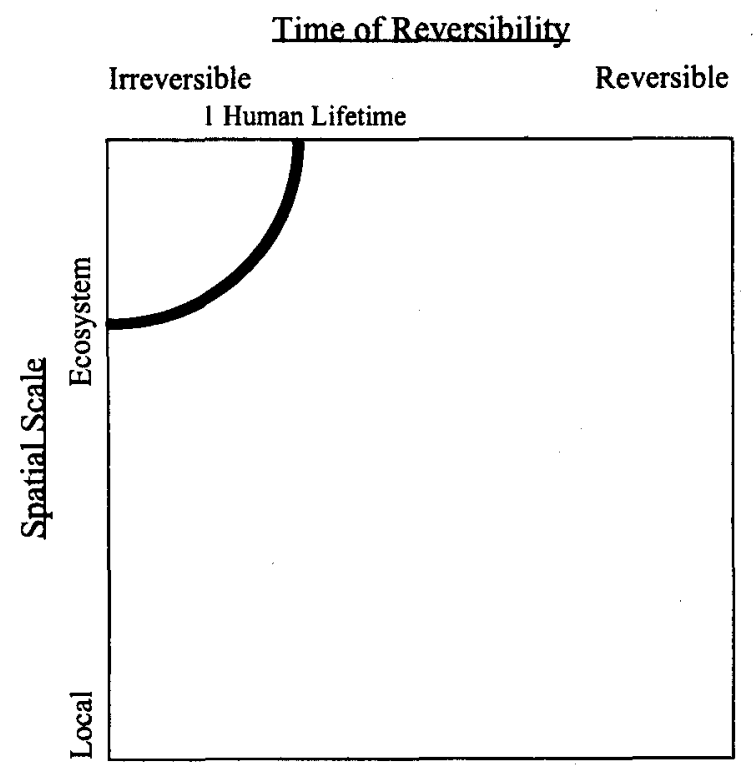

Fig. 2. Ecologist's version.

now introduce a more precise and detailed version. The ecologist's version (Figure 2) superimposes hierarchical concepts on the square. $^{40}$ We can interpret the idea of reversibility as the time required for damage to an ecological system to correct itself. We also can interpret the magnitude of effects as a matter of the spatial extent of the damage to an ecological system. Since the systems are not conceived as stable, but in constant, multi-levelled change, we must distinguish change that affects the integrity of large ecological systems from changes that do not. Generally speaking, the integrity of a system is maintained if the pace of change in that system is sufficiently slow to allow species and communities to adapt to those changes. If so, we say that the system maintains its health or integrity, despite constant change. While space does not allow us to explore all of the consequences of this conceptualization, I believe it provides a general framework for integrating a dynamic ecology into discussions of environmental policy decisions. Therefore, it also provides the beginnings of an answer to Botkin's concern that we must distinguish acceptable from unacceptable change.

40. Id. 
The next step is for ecologists to elaborate the hierarchical concepts of temporal pace and spatial scale and to do so, not in terms of general theory, but in the particular, local contexts in which particular ecological systems with unique organizational structures are unduly stressed by human activities. New Ecology, which emphasizes dynamism and avoids concepts based in personalistic organicism like the "strategy" of ecosystems, is ideally positioned to contribute to this important task. Still, the New Ecologists' justifiable emphasis on change in ecological systems must be balanced with a concerted effort to understand the pace and scale of that change. We cannot understand the importance of creative, self-organizing activity of ecosystems - or what we mean by ecosystem integrity - unless we also understand the concept of relative stability in dynamic multiscalar systems. 